\title{
ADIKUASA PERDAGANGAN TIONGKOK: TIONGKOK DALAM REVOLUSI INDUSTRI 4.0 DI INDONESIA (TINJAUAN SEJARAH SOSIAL-EKONOMI PEDAGANG TIONGKOK DI INDONESIA)
}

\author{
Alifi Nur Prasetia Nugroho, Rini Riris Setyowati \\ Pendidikan Sejarah, Program Pascasarjana, \\ Universitas Negeri Yogyakarta \\ alifinur.pn@uny.ac.id,riniriris456@gmail.com
}

\begin{abstract}
ABSTRAK
Etnis Tiongkok merupakan bagian dari entitas budaya Indonesia. Hubungan ini terjalin sejak jaman Kerajaan Hindu-Budha di Nusantara. Rekatnya hubungan Tiongkok secara keseluruhan dengan Indonesia diawali oleh faktor ekonomi. Hiruk pikuk jalur Sutra pada masa Dinasti Han hingga perdagangan di Malaka menambah kedekatan dua negara ini hingga sekarang. Letak geografis yang strategis dalam peta perdagangan dunia menjadikan Tiongkok lahir sebagai kekuatan tandingan Barat dari Asia. Melalui metode studi pustaka dengan menggunakan berbagai sumber diharapkan dapat memberi gambaran pengaruh ekonomi signifikan Tiongkok di kancah dunia Tiongkok hadir keunikan tersendiri yang tidak dimiliki oleh negara lain. Kekuatan nilai-nilai tradisional-budaya diiringi perkembangan IPTEK merupakan modal Tiongkok menghadapi persaingan peradaban dunia. Tiongkok dapat bertahan dalam berbagai macam tekanan dan perubahan jaman. Kini pada abad 21, Tiongkok dengan segala kesiapannya telah masuk keseluruhan bagian lini kehidupan masyarakat Indonesia.
\end{abstract}

Kata Kunci: Indonesia, Tiongkok, Revolusi 4.0

\begin{abstract}
Ethnic Chinese are part of Indonesian cultural entities. This relationship has ever existed since the Hindu-Buddhist kingdom in the archipelago. Economic factors preceded the stickiness of Chinese relations. The Silk Road during the Han Dynasty to trade in Malacca added to the closeness of the two countries to the present. The strategic geographical position on the map of world trade made Tiongkok-born as a rival power to the West from Asia. Through the literature study method using various sources, it can provide a significant assessment of the Chinese economy on the world stage. Tiongkok presents unique features which are not provided by other countries. The strength of traditional-cultural values accompanied by the development of science and technology in Tiongkok's capital in facing the competition of world civilizations in various fields. This makes Tiongkok able to endure various kinds of pressures and changes so as not to be eroded by changing times.
\end{abstract}

Keywords: Indonesia, Tiongkok, Revolution 4.0 


\section{PENDAHULUAN}

Masyarakat Tiongkok telah menjalin hubungan dengan Nusantara (sebelum Indonesia) sejak kerajaan Hindu-Budha berdiri. Lalu-lintas perdagangan di Malaka yang semakin ramai tidak dapat menghindarkan Nusantara dari hubungan dengan dunia luar. Sebagai daerah penghasil komoditas rempah dan bahanbahan kebutuhan lainnya, Nusantara menjadi sasaran empuk para pedagang dalam pusaran perekonomian. Mobilitas para pedagang Tiongkok kian cepat dipengaruhi oleh aktivitas jalur perdagangan yang menghubungkan Tiongkok dengan daratan Eropa dan Timur Tengah. Sutra sebagai komoditas paling laku saat itu membawa angin segar bagi perkembangan perekonomian masyarakat Tiongkok. Kemajuan di bidang ekonomi menambah rasa percaya diri masyarakat Tiongkok untuk tinggal dan menetap di tempat-tempat baru yang mereka tuju.

Dominasi masyarakat Tiongkok telah terasa ketika mereka menetap di Indonesia. Pada masa penjajahan Belanda, Tiongkok menduduki golongan atau strata sosial yang lebih tinggi dibanding dengan pribumi. Mereka tinggal dalam sebuah komunitas eksklusif yang biasa disebut dengan Pecinan (kampong Tiongkok) yang mana seluruh isi kampong terdiri dari masyarakat Tiongkok. Selain itu masyarakat Tiongkok pada saat itu memegang tampuk kekuasaan perdagangan di
Indonesia termasuk pada perdagangan batik. Sarekat Dagang Islam (SDI) berdiri sebagai reaksi dalam menghadapi persaingan dagang batik masyarakat pribumi dengan pedagang Tiongkok. Sarekat Dagang Islam yang kemudian bertransformasi menjadi Sarekat Islam berusaha mengatasi ketertinggalan dalam perdagangan Batik dengan Cina. Namun, kekuatan perdagangan Tiongkok sudah terlanjur mengakar kuat hingga dapat dirasakan sampai sekarang.

Masyarakat Tiongkok yang menetap di Indonesia telah menjadi bagian dari masyarakat Indonesia itu sendiri. Meskipun demikian hubungan antara etnis Tionghoa dengan masyarakat Indonesia bukan tanpa cela. Benihbenih persaingan antara masyarakat Indonesia dengan Tiongkok telah lama dirasakan. Pada tahun 1998 pernah terjadi kerusuhan di Solo dan Jakarta yang mana sasarannya adalah orang Tiongkok. Menanggapi kejadian tersebut Gus Dur sewaktu menjabat sebagai Presiden RI ke 4, mengeluarkan Instruksi Presiden (Inpres) No. 6/2000 pada 7 Januari 2000 yang isinya mencabut Inpres No. 14/1967. Kebijakan Gus Dur melahirkan kebebasan etnis Tionghoa dalam menjalankan ritual keagamaan, adat istiadat, serta memperbolehkan

mengekspresikan terhadap kebudayaannya di Indonesia.

Pada abad 21, dominasi masyarakat cina dapat dirasakan menjalar dan semakin mengakar 
pada segala bidang. Tidak hanya pada Indonesia, namun juga dirasakan oleh dunia. Lahirnya Tiongkok sebagai kekuatan dari dunia Timur menjadi pesaing berat dunia Barat. Tiongkok dengan wacana ingin menghidupkan kembali jalur sutra kini semakin percaya diri untuk membuktikan bahwa benar-benar dapat mewujudkan teori sebagai kekuatan penguasa dari Timur. Berbanding terbalik dengan Tiongkok yang sudah siap tegak berdiri sebagai pesaing Barat, Indonesia harus menerima ketidaksiapan dalam menghadapi perubahan dunia.

Indonesia dalam pusaran perdagangan mau tidak mau harus mengakui bahwa telah dikuasai dan dipimpin oleh Tiongkok. Segala sesuatu mulai dari makanan, produk rumah tangga, elektronik dan lain-lain, merupakan buatan Tiongkok. Masyarakat Indonesia hingga saat ini masih sebagai konsumen saja dan belum dapat memproduksi. Pasar Indonesia dibanjiri oleh produk-produk dari Tiongkok. Masuknya barangbarang Tiongkok ke Indonesia dengan mudah melalui transaksi $e$ commerce pada aplikasi-aplikasi seperti Shopee, Lazada, Alibaba dan lain-lain menambah deretan panjang ketertinggalan Indonesia dikancah perdagangan Internasional. Segala sesuatu yang berlabel Tiongkok dapat dengan sangat mudah dijumpai dalam kehidupan sehari-hari seperti pada sikat gigi, baju, bolpoin, HP, TV, Motor dan lain sebagainya.
Kekuatan Tiongkok yang semakin lama kian berkembang di Indonesia merupakan ancaman sekaligus tantangan bagi Indonesia untuk bangkit dari keterpurukan dalam menghadapi revolusi 4.0. Kajian Indonesia dengan Tiongkok sangat menarik apalagi berkaitan dengan menghadapi revolusi 4.0. Maka, pada tulisan ini penulis tertarik untuk membahas lebih dalam lagi mengenai "Adikuasa Perdagangan Tiongkok di Indonesia: Tiongkok dalam Revolusi Industri 4.0 di Indonesia" dengan tinjauan sejarah ekonomi, sosial masyarakat Tiongkok di Indonesia.

\section{PEMBAHASAN}

\section{Pedagang Tiongkok Sebelum Indonesia Merdeka}

Masyarakat Tiongkok telah dikenal sebagai masyarakat yang lihai dalam hal perdagangan. Bakat berdagang tersebut seakan telah diwariskan oleh nenek moyang mereka. Letak geografis Tiongkok dalam peta dunia yang berada di tengah dengan luas daratan yang luas, memberi dampak yang sangat positif terhadap kehidupan masyarakat Tiongkok. Pertumbuhan perdagangan mereka berawal dari dibukanya jalur perdagangan dengan Timur Tengah dan negara-negara lainnya yang dikenal dengan Jalur Sutra. Jalur inilah yang mengantarkan masyarakat Tiongkok mendunia. Selain itu sifat dari masyarakat Tiongkok yang mudah menyesuaikan diri dengan lingkungan semakin membawa 
dampak positif bagi perkembangan perekonomian mereka.

Tiongkok dengan Nusantara sendiri telah menjalin hubungan sejak masa kerajaan yang dibawa oleh para pedagang. Dibuktikan dengan banyaknya sumber-sumber sejarah kerajaan Hindu-Budha yang digunakan sebagai literasi seperti halnya parung batu di Pasemah, Sumatera Selatan yang memiliki kemiripan dengan patung yang terdapat pada kuburan Jenderal Huo K'iuping berangka tahun 117 SM dan benda keramik di Sumatera, Jawa, dan Kalimantan berangka tahun 45 SM. ${ }^{1}$ Kedatangan para pedagang kemudian di ikuti dengan kedatangan utusan-utusan. Seorang musafir Tiongkok beragama Budha datang ke Nusantara. Kedatangan Fa-Hsien yaitu pada tahun $413 \mathrm{M}$, disusul oleh Dinasti Sung (420-179) dan Dinasti Liang (520-527). ${ }^{2}$ Berita Tiongkok, I-Tsing yang dikirim sebagai utusan ke kerajaan Kalingga, Mataram dan Majapahit dan lain-lain. ${ }^{3}$

Hubungan perdagangan yang dilakukan oleh Tiongkok dan Nusantara dibuktikan dengan penemuan benda-benda arkeologi berupa keramik, gerabah, perhiasan dan lain-lain yang diduga berasal dari Tiongkok. Berlanjut pada masa Kerajaan Islam, bukti

\footnotetext{
1 Tri Wahyuning M. Irsyam. Golongan Etnis Tiongkok sebagai Pedagang Perantara di Indonesia (Seminar Sejarah Nasional IV di Yogyakarta, tanggal 16-19 Desember: 1985). (Jakarta: Depdikbud), hlm. 2.
}

hubungan tersebut dapat dilihat dari mulai kedatangan Laksamana Cheng Ho ke Malaka pada 1409.4 Ramainya lalu lintas pelabuhan Malaka membuat para pedagang Tiongkok mulai banyak menetap di Nusantara dan berbaur dengan penduduk setempat.

Hubungan yang telah lama terjalin erat antara bangsa Tiongkok dengan masyarakat Nusantara ini membawa kaum Tiongkok menjadi bagian dari masyarakat Nusantara. Hal ini ditunjukkan dengan munculnya perkampungan-perkampungan

Tiongkok. Tidak hanya bertujuan untuk mengambangkan perdagangan, namun mereka juga membawa dan mengembangkan Agama serta tradisi. Selain membangun kantung-kantung perdagangan yang berlokasi dekat dengan pelabuhan, mereka juga menghidupkan tradisi-tradisi ritual Tiongkok di dalamnya dengan mendirikan tempat-tempat peribadahan di tengah lingkungan tempat tinggal.

Pelabuhan besar yang dikuasai oleh Tiongkok dan cukup dikenal pada saat itu berada di Tuban dan Semarang. Tidak hanya bermukim di daerah-daerah pelabuhan, masyarakat Tiongkok juga menghuni berbagai daerah di wilayah Nusantara yang memiliki ciri tersendiri dan masih hingga

\footnotetext{
2 Ibid.,

3 Ibid.,

4 Tan Ta Sen. Cheng Ho: Penyebar Islam dari Tiongkok ke Nusantara. (Yogyakarta: Kompas, 2010), hlm. 251.
} 
saat ini. Pola pemukiman ini biasa disebut dengan pecinan. Kelompok pecinan ini biasanya berada di dekat dengan pasar. Sebagian besar dari mereka merupakan kaum pedagang, sehingga di mana roda perekonomian suatu daerah berpusat di situlah tempat yang biasanya mereka pertimbangkan untuk ditempati. Pembentukan pecinan ditujukan agar pemerintah kolonial dapat lebih mudah mengawasi aktivitas ekonomi dan segala tindakan sosial komunitas Tiongkok guna mengantisipasi kejadian pemberontakan orangorang Tiongkok terhadap kolonial tahun 1742.5

Masyarakat Tiongkok hidup berdampingan dengan masyarakat pribumi. Etnis Tionghoa ini juga ikut berperan dalam pembentukan dan pengembangan budaya Jawa. ${ }^{6}$ Jika dikatakan mereka hidup berdampingan dengan damai maka tentu tidak selamanya terjadi. Sebagai mayoritas, tidak dapat dipungkiri bahwa terkadang perasaan rasis terhadap masyarakat Tiongkok muncul. Salah satu penyebabnya yaitu keberhasilan dan kesuksesan ekonomi masyarakat Cina di atas penduduk pribumi. Pada sekitar tahun 1912 terjadi persaingan

\footnotetext{
5 Eka Deasy Widyaningsih. Masyarakat Tiongkok Bolong Sudiroprajan (Studi Interaksi Sosial Masyarakat Tiongkok-Jawa di Surakarta Pada Pertengahan-akhir Abad XX). Skripsi. Surakarta: UNS, hlm. 13.

6 Rustopo. 2007. Menjadi Jawa: Orang-orang Tionghoa dan Kebudayaan
}

antar pedagang batik lokal dengan pedagang batik Cina. Hal ini tentu menunjukkan bahwa masyarakat Cina meskipun sebagai minoritas namun dapat satu tingkat di atas penduduk pribumi.

Untuk mempertahankan citra pribumi sebagai mayoritas yang tidak semestinya berada di posisi bawah kaum minoritas, dibentuk Sarekat Dagang Islam (SDI). Tujuan dari pembentukan SDI salah satunya yaitu memajukan perdagangan rakyat pribumi. ${ }^{7} \mathrm{Hal}$ tersebut didukung dengan pernyataan Coser bahwa sebenarnya perselisihan dan persaingan berhubungan dengan nilai-nilai atau tuntunan-tuntunan berkenaan dengan status, kuasa, dan sumber-sumber tertentu hingga mendorong suatu kelompok untuk ingin menonjol, menghancurkan serta menunjukkan kekuatan mereka. ${ }^{8}$ Penguasaan terhadap pasar Batik ini merupakan bukti perkembangan roda perekonomian masyarakat Tiongkok lebih cepat dari kaum pribumi. Dominasi masyarakat Tiongkok dalam bidang ekonomi ini kemudian terus hingga menyebabkan tampuk perdagangan dipegang oleh kaum minoritas Tiongkok.

Jawa di Surakarta 1895-1998. (Yogyakarta: Ombak), hlm. 2.

7 Endang Muryanti. Muncul dan Pecahnya Sarekat Islam di Semarang 1913-1920. Jurnal Paramita Vol. 20 No. 1 Januari 2010, hlm. 22.

8 Margaret M. Polome. Sosiologi Kontemporer. (Jakarta: Rajawali Persada, 1945), hlm. 107-108. 


\section{Pedagang Tiongkok di Indonesia Setelah Kemerdekaan}

Pasca dikumandangkan proklamasi kemerdekaan Indonesia, masyarakat Tiongkok masih tetap tinggal dalam naungan negara Indonesia. Lahirnya Indonesia sebagai negara baru tidak banyak mempengaruhi aktivitas perdagangan kaum pedagang Tiongkok di Indonesia. Para pedagang-pedagang Tiongkok masih melakukan kegiatan perdagangan seperti biasanya. Namun demikian bibit-bibit rasis, sedikit-banyak masih tertanam dalam benak masyarakat Indonesia terhadap masyarakat Tiongkok. Ketegangan antara orang Cina dengan penduduk pribumi terus tumbuh sebagai akibat dari meluasnya jarak antara yang kaya dan yang miskin dalam negara serta kebijakan-kebijakan yang diterapkan dalam negara. ${ }^{9}$

Pada tahun1972-1998 terjadi serangkaian tragedi konflik rasial di Surakarta. Banyak gedunggedung perkantoran, pertokoan, atau rumah-rumah yang hangus terbakar serta kendaraankendaraan transportasi pun tidak luput dari amukkan massa. Penyebab dari konflik rasial di Surakarta disebabkan oleh faktor; 1) faktor ekonomi, 2) faktor historis dan, 3) faktor politik.10 Faktor yang paling dominan adalah

\footnotetext{
9 Onghokham. Anti Cina, Kapitalisme Cina, dan Gerakan Cina: Sejarah Etnis Cina di Indonesia. (Jakarta: Komunitas Bambu, 2008)hlm. 24.

10 Yahya Aryanto Putro, Hamdan Tri Atmaja, Ibnu Sodiq. Konflik Rasial Antara Etnis Tionghoa Dengan Pribumi
}

faktor ekonomi yaitu fenomena ekonomi modern dan tradisional, masalah perburuhan, masalah marginalisasi kaum miskin dan krisis moneter menjadi pemicu terjadinya konflik rasial tersebut. Kejadian tersebut tentu mengganggu stabilitas perekonomian pedagang Tiongkok. Mereka sebagai "korban" rasisme dari kelompok mayoritas terpaksa harus mengalami banyak kerugian hingga trauma.

Kejadian anarkis dengan mengusung slogan "anti-Tiongkok" meluas ke berbagai wilayah di Indonesia. Seperti teori domino, kerusuhan dengan cepat menjalar ke Boyolali, Salatiga, Ambarawa, Banyubiru, Candi dan Semarang serta Jakarta. ${ }^{11}$ Para simpatisan melempari semua rumah dan toko milik Tionghoa. Selain itu juga terjadi penjarahan dan pemerkosaan terhadap perempuan-perempuan etnis Tiongkok. Beberapa di antaranya memilih untuk mengungsi ke luar negeri, untuk mengamankan diri. Meskipun sempat goyah perdagangan masyarakat Tiongkok di Indonesia namun tidak lama kemudian roda perdagangan kembali dipegang oleh kelompok Tiongkok.

Revolusi Industri 4.0 di Indonesia

Revolusi industri di Indonesia telah dimulai sejak zaman

Jawa di Surakarta Tahun 1972-1998. Jurnal. Journal of Indonesian History Vol. 6 Januari 2017, hlm 67.

11 Benny Setiono. G. Tionghoa Dalam Pusaran Politik. (Jakarta: Elkasa, 2002), hlm. 27. 
pemerintahan Hindia-Belanda. Induk dari terjadinya revolusi Industri dimulai dari Inggris. Perkembangan Industri abad 18 ini dimulai sejak adanya penemuan mesin uap, flying shuttle (alat tenun) dan water frame. ${ }^{12}$ Adapun sebab dari kepemimpinan Inggris dalam Revolusi Industri dipengaruhi oleh penguasaan Inggris terhadap negara-negara koloninya. Sebagai pusat kekuatan besar yang dibuktikan dengan kemenangan dalam Perang Tujuh Tahun dengan Perancis memberikan kepercayaan diri Inggris meningkat dalam supremasi maritim dan perdagangan dunia. Hegemoni perdagangan Inggris menyebar dan berkembang pesat di pasar dunia setelah $1763 .{ }^{13}$

Terjadinya Revolusi Industri sangat mempengaruhi perubahanperubahan cepat dalam berbagai bidang kehidupan masyarakat, tanpa terkecuali bidang ekonomi. ${ }^{14}$ Sebagian besar negara menggantungkan perekonomian mereka pada sektor pertanian. Revolusi Industri membawa perubahan yang membuat migrasi besar-besaran pada seluruh kehidupan. Semenjak terjadi revolusi industri tidak lagi menanamkan minat pada bidang pertanian, mereka lebih memilih migrasi ke Kota untuk bekerja

12 Huton Webster. World History:

Sejarah Dunia Lengkap. (Yogyakarta: Indoliterasi, 2016), hlm. 581.

13 Ibid., hlm. 580. sebagai pekerja pabrik. Perkembangan industri pabrik memaksa untuk melakukan transaksi pasar secara luas. Hingga dampak dari hal tersebut adalah munculnya keinginan negaranegara besar untuk memperluas wilayah koloni mereka hingga muncul paham kapitalisme.

Penguasaan Belanda atas Indonesia tidak dapat dilepaskan dari pengaruh Revolusi Industri. Namun jauh sebelum Revolusi Industri terjadi Belanda sendiri telah menanamkan pengaruhnya di Nusantara dengan melalui Vereenigde Oost Indische Comagnie (VOC) yang terbentuk pada 1602.15 Revolusi Industri di Nusantara sebenarnya dibawa oleh Belanda. Melalui Belanda, Nusantara mengalami Revolusi Industri yang pertama ditandai dengan penggunaan mesin Uap. Di bawah payung kolonial Belanda, Indonesia merasakan Revolusi Industri meski diiringi dengan penderitaan.

Tahap Revolusi Industri selanjutnya di Indonesia yaitu mulai disempurnakan dengan munculnya sarana-sarana transportasi umum dan komunikasi di Nusantara. Trem dan Kereta membawa wajah baru bagi masyarakat pribumi yang berpengaruh cukup signifikan terhadap perkembangan kehidupan pada sektor

14 Juma' De Putra. Revolusirevolusi Paling Spektakuler di Dunia. (Yogyakarta: IRCiSoD, 2014), hlm. 33

15 Sartono Kartodirdjo. Pengantar

Sejarah Indonesia Baru: 1500-1900. (Jakarta: Gramedia, 1987), hlm.78 
perekonomian. Selanjutnya setelah lepas dari belenggu penjajahan pada abad XX, Indonesia digegerkan dengan adanya wacana "globalisasi". Segala bentuk sajian tulisan maupun ucapan yang di bumbui oleh kata "globalisasi" laku di pasaran. Seakan kata globalisasi menjadi momok yang menakutkan pada masyarakat Indonesia pada saat itu.

Revolusi pada tataran ke tiga tidak lagi berwujud dalam bentuk fisik seperti penemuan mesinmesin yang kemudian berdampak pada kegiatan perekonomian. Namun lebih pada tatanan kehidupan manusia dunia yang mengglobal. Globalisasi menggandeng paham liberalisme. Arus globalisasi dibarengi dengan kemajuan teknologi digital. Maka perubahan yang ditimbulkan pun mempengaruhi pola pikir manusia. Seperti dua tahap revolusi yang lain, revolusi ini juga tidak dapat dihindari oleh masyarakat Indonesia.

Globalisasi masih dapat dirasakan hingga sekarang. Wacana Revolusi Industri 4.0 merupakan lanjutan tahap Globalisasi. Konsep industri 4.0 dicetuskan pertama kali pada 2011 oleh Jerman, yang kemudian menjadi tema utama pada pertemuan World Economic Forum (WEF) 2016 di Davos, Swiss. ${ }^{16}$ Revolusi industri 4.0 harus

16 Dani Jumadil Akhir. Percepat Revolusi Industri 4.0 Kemenprin Gandeng Cina. Koran Online. Diterbitkan pada Senin 15 Mei 2017 07:07 WIB. Tersedia di https://economy.okezone.com/read/201 dihadapi oleh bangsa Indonesia dengan cerdas agar tidak tertinggal semakin jauh. Tentu saja untuk menghadapi revolusi ini, pemerintah perlu untuk memperhatikan dan menimbang betul kebijakan-kebijakan yang nantinya dapat diambil dan diterapkan. Terobosan baru yang sedang digadang dalam menyukseskan revolusi industri 4.0 yaitu pengembangan teknologi kecerdasan buatan Artifical Intellegence. Maka dari itu, siap tidak siap, Bangsa Indonesia tidak bisa lari dari adanya revolusi ini.

\section{Tiongkok di Indonesia dalam Revolusi Industri sampai Revolusi 4.0}

Revolusi Industri merupakan puncak dari lepasnya belenggu Dogma Agama di Barat (Masa Kegelapan). Revolusi Industri menjadi satu penyebab utama kelahiran revolusi-revolusi lain. Menyambung hal itu, revolusi Industri yang berdampak pada seluruh dunia mendorong Tiongkok lahir sebagai negara adidaya. Meskipun kita tidak dapat menutup mata jika sebenarnya kekuatan penguasaan di bidang perekonomian khususnya pada bidang perdagangan telah lama digenggam oleh Tiongkok melalui perantara jalur sutera. Dalam modernitas, Tiongkok seakan mengikuti perkembangan dan mampu bertahan dari gelombang

7/05/15/320/1690966/percepatrevolusi-industri-4-0-kemenperingandeng-tiongkok. Diakses pada 18 Desember 2018. 
Revolusi Industri pertama hingga pada tahap Revolusi Industri 4.0.

Dampak revolusi Industri yang mampu membangkitkan Tiongkok pada kancah perekonomian dunia dirasakan pula oleh Indonesia. Hingga kini masyarakat Tiongkok telah menjadi bagian masyarakat Indonesia dan berbaur menjadi satu entitas budaya Indonesia. Namun, dominasi ekonomi khususnya perdagangan Tiongkok di Indonesia sangat kuat. Konsistensi Tiongkok dalam dunia perekonomian sesuai dengan prinsip ekonomi mereka yaitu perdagangan berguna untuk mencari keuntungan (laba) yang sebesar-besarnya terus diterapkan, sehingga prinsip ini menjadi simbol kekayaan yang dapat digunakan untuk menunjukkan status sosial. ${ }^{17}$ Terbukti status kelas sosial yang dituai dari prinsip ekonomi tersebut pernah dirasakan oleh masyarakat Tiongkok di Indonesia pada masa penjajahan Belanda. Pada saat itu Tiongkok mampu menduduki strata di atas pribumi di bawah orang-orang Belanda.

Menilik dari kesuksesan Tiongkok pada masa lampau, menghadapi Revolusi Industri 4.0, Tiongkok digadang sebagai pemimpin kekuatan dunia dimasa mendatang. Setelah tampuk kekuasaan dipegang oleh Amerika, Goldman memproyeksikan bahwa

${ }^{17}$ Ann Wan Seng. Loc.cit.

18 Martin Jacques. When Tiongkok Rules The World. (Jakarta: Kompas, 2011), hlm. 3. perekonomian terbesar tahun 2050 akan dipimpin oleh Tiongkok, disusul oleh AS dan India agak jauh di belakang, lalu Brazil, Meksiko, Rusia, dan Indonesia. ${ }^{18}$ Meskipun Indonesia diperkirakan masuk dalam sepuluh besar kekuatan perekonomian dunia, namun hal itu terjadi tentunya jika Indonesia benar-benar dapat memaksimalkan sumber daya alam dan manusia dengan baik.

Tiongkok merupakan salah satu negara yang memiliki karakteristik yang unik. Jaques menyatakan ada delapan karakteristik yang menjadi identitas Tiongkok; (1) Tiongkok bukan negara dengan konsep tradisional namun sebuah negara peradaban, (2) Tiongkok akan melakukan hubungan dengan Asia Timur menggunakan kerangka sistem negara upeti, (3) kekuatan ras dan etnis, (4) pergerakan secara terus menerus karena memiliki wilayah yang sangat luas, (5) watak tata politik Tiongkok sangat spesifik, (6) kecepatan transformasi Tiongkok dalam modernitas, (7) masa lalu pemerintahan rezim komunis ${ }^{19}$, dan (8) Tiongkok masih dalam proses mengombinasi antara negara maju dan negara berkembang.

Bermodal

delapan karakteristik yang dimiliki oleh Tiongkok, maka bisa saja

19 Jacques memaparkan bahwa rezim komunis di Tiongkok berbeda dengan di Soviet karna menganggap lebih pluralistic dan fleksibel hingga mampu menciptakan modernitas di Tiongkok. 
modernitas Tiongkok terjadi secara fundamental dari segala aspek kehidupan. Agar tidak tertinggal jauh bahkan tergilas, Indonesia dalam menghadapi Revolusi Industri 4.0 tengah berupaya bangkit dari keterpurukan ekonomi. Pekerja dan pasar menjadi kunci utama dalam terwujudnya digitalisasi ekonomi yang merupakan hasil Revolusi Industri 4.0.20 Fokus Indonesia dalam Revolusi Industri 4.0 terjadi dalam sektor manufaktur, yaitu; (1) industri otomotif, (2) industri tekstil, (3) industri makanan dan minuman, (4) industri kimia, dan (5) industri elektronik. ${ }^{21}$

Mengutip dari pernyataan Menteri Industri, Airlangga menyatakan bahwa Revolusi 4.0 merupakan era di mana terjadi konektivitas secara nyata antara manusia, mesin dan data. ${ }^{22}$ Dituntut kesiapan manusia dalam menghadapi konektivitas dengan mesin dan data. Sebagai negara dengan jumlah penduduk terbanyak yaitu masuk dalam lima

20 Agi. Indonesia Gandeng Tiongkok Demi Hadapi Revolusi Industri 4.0. Koran Online. Di publish pada Kamis, 08 Maret 2018. Tersedia di http://www.cnnindonesia.com/ekonomi/ 20180307213329-92-281270/indonesiagandeng-tiongkok-demi-hadapi-revolusiindustri-40. Diakses pada 18 Desember 2018.

21 Dni. Ini 5 Sektor Industri yang Jadi Fokus Jokowi di Era Digital. Koran Online. Di publish pada Rabu, 04 April 2018. Tersedia di http://finance.detik.com/industri/d3952581/ini-5-sektor-industri-yang-jadifokus-jokowi-di-era-digital. Diakses pada 18 Desember 2018. besar dunia, maka Indonesia merupakan sasaran pasar yang empuk bagi produsen penghasil teknologi digital. Jika ditilik secara rinci, segala sesuatu yang dipakai oleh masyarakat Indonesia hampir semuanya berlabel "made in Tiongkok". Dominasi Tiongkok dalam segala lini kehidupan masyarakat Indonesia terjadi tanpa pernah teperhatikan. Apabila terus terjadi peningkatan konsumerisme tanpa dapat menjadi produsen kemungkinan Revolusi Industri 4.0 dapat menggilas Indonesia.

Smart machines may make higher G.D.P possible, but they will also reduce the demand for people, including smart people. ${ }^{23}$ Meskipun kekuasaan tidak dapat dilepaskan dari faktor ekonomi termasuk tingginya GDP suatu negara, namun manusia merupakan kunci utama agar tidak terjerumus di dalam kemajuan. Manusia merupakan pencipta dari mesin-mesin pintar, namun perlu diperhatikan bahwa manusia juga tidak boleh kalah pintar dari mesin tersebut.

22 Sakina Rakhma Diah S. Dukung Revolusi Industri 4.0 Komputasi Awan Jadi Faktor Penting. Koran Olnine. Di publish pada 25 Oktober 2018. Tersedia di https://ekonomi.kompas.com/read/2018 /10/25/123614926/dukung-revolusiindustri-30-komputasi-awan-jadi-faktorpenting

23 Paul Krugman. A New Industrial Revolution: The Rise of Robots. Majalah Online. The New York Times Company, 2013. Tersedia di https://truthout.org/authors/paulkrugman/page/2/. Akses pada 27 Desember 2018 pukul 22:02. 
Mengenai masalah Revolusi Industri 4.0 di Indonesia, meskipun Cina digadang dapat mendominasi kekuatan besar dunia, manusia PENUTUP

Revolusi merupakah situasi yang wajar jika terjadi. Tanpa ada revolusi segala sesuatu menjadi statis. Namun sebagai manusia, dalam menghadapi revolusi perlu memperhatikan dampak positif dan negatif yang muncul sesudah revolusi berlangsung. Terkait dengan perubahan, faktor ekonomi menjadi faktor dominan yang berperan di dalamnya. Perekonomian merupakan salah satu aspek yang dinamis. Segala sesuatu dalam kehidupan manusia dapat berubah karena faktor ekonomi. Salah satu revolusi yang berpengaruh terhadap perekonomian adalah Revolusi Industri. Sejak Abad ke 17, revolusi ini terus berkembang hingga sekarang masuk pada tahap yang disebut dengan Revolusi Industri 4.0.

Munculnya Revolusi Industri 4.0 semakin membuat dominasi serta sekat yang kentara antara yang kuat dengan yang lemah. Indonesia sendiri telah mengalami revolusi baik secara langsung maupun tidak sejak sebelum merdeka. Sebagai negara yang pernah merasakan pahitnya penjajahan dari beberapa negara, Revolusi Industri 4.0 tidak boleh menjadi salah satu dari penjajah modern yang muncul kembali saat sudah merdeka. Revolusi Industri $4.0 \mathrm{di}$ Indonesia tidak dapat yang cerdas harus dipersiapkan oleh Indonesia jika benar-benar tidak ingin tertinggal dalam modernitas.

dihindari. Manusia sebagai pencipta mesin-mesin digital pintar menjadikan dirinya sendiri bergantung pada mesin tersebut. Meskipun sering dianggap sebagai alat-alat yang membantu manusia, namun mesin-mesin pintar tersebut seperti candu bagi yang membuat. Jika tidak mengikuti maka tertinggal atau tergilas dengan kemajuan dunia. Maka, manusia sebagai pencipta harus cerdas menghadapi hasil karyanya sendiri.

Kekuasaan Tiongkok yang semakin besar dengan kecanggihan-kecanggihan yang mengikutinya serta kepandaian dalam manajemen perekonomian menjadi fokus perhatian dunia di era Revolusi Industri 4.0. Wacana tentang Tiongkok sebagai negara yang kuat dari Timur dapat saja terjadi, melihat kesiapan Tiongkok dalam menjadi pesaing AS pada pasar Global. Barang-barang dari Tiongkok kini telah menguasai pasar global, termasuk mesinmesin digital yang canggih. Hasilhasil digitalisasi dari berbagai macam aspek yang diciptakan oleh Tiongkok juga telah merambah masuk ke pasar Indonesia. Apabila masyarakat Indonesia tidak cerdas menyikapi perubahan tersebut, maka sulit untuk bersaing dengan Tiongkok dan kembali berada di bawah Tiongkok seperti yang terjadi sepanjang sejarah pedagang Tiongkok di Indonesia. 


\section{DAFTAR PUSTAKA}

Ann Wan Seng. (2007). Rahasia Bisnis Orang Cina. Jakarta: Hikmah.

Benny Setiono. G. (2002). Tionghoa Dalam Pusaran Politik. Jakarta: Elkasa

Huton Webster. (2016). World History: Sejarah Dunia Lengkap. Yogyakarta: Indoliterasi.

Juma' De Putra. (2014). Revolusirevolusi Paling Spektakuler di Dunia. Yogyakarta: IRCiSoD.

Martin Jacques. (2011). When Tiongkok Rules The World. Jakarta: Kompas.

Onghokham. (2008). Anti Cina, Kapitalisme Cina, dan Gerakan Cina: Sejarah Etnis Cina di Indonesia. Jakarta: Komunitas Bambu.

Sartono Kartodirdjo. (1987). Pengantar Sejarah Indonesia Baru: 1500-1900. Jakarta: Gramedia.

Tan Ta Sen. (2010). Cheng Ho: Penyebar Islam dari Tiongkok ke Nusantara. Yogyakarta: Kompas.

Tri Wahyuning M. Irsyam. Golongan Etnis Tiongkok sebagai Pedagang Perantara di Indonesia (Seminar Sejarah Nasional IV di Yogyakarta, tanggal 16-19 Desember: 1985). Jakarta: Depdikbud.

Eka Deasy Widyaningsih. Masyarakat Tiongkok Bolong Sudiroprajan (Studi Interaksi Sosial Masyarakat TiongkokJawa di Surakarta Pada Pertengahan-akhir Abad XX).
Skripsi. Surakarta: UNS, hlm. 13.

Yahya Aryanto Putro, Hamdan Tri Atmaja, Ibnu Sodiq. Konflik Rasial Antara Etnis Tionghoa Dengan Pribumi Jawa di Surakarta Tahun 1972-1998. Jurnal. Journal of Indonesian History Vol. 6 Januari 2017, hlm 67.

Agi. Indonesia Gandeng Tiongkok Demi Hadapi Revolusi Industri 4.0. Koran Online. Di publish pada Kamis, 08 Maret 2018. Tersedia di http://www.cnnindonesia.co $\underline{\mathrm{m} / \text { ekonomi/201803072133 }}$ 29-92-281270/indonesiagandeng-tiongkok-demihadapi-revolusi-industri-40. Diakses pada 18 Desember 2018.

Dani Jumadil Akhir. Percepat Revolusi Industri 4.0 Kemenprin Gandeng Cina. Koran Online. Diterbitkan pada Senin 15 Mei 2017 07:07 WIB. Tersedia di https://economy.okezone.co $\mathrm{m} / \mathrm{read} / 2017 / 05 / 15 / 320 / 1$ 690966/percepat-revolusiindustri-4-0-kemenperingandeng-tiongkok. Diakses pada 18 Desember 2018.

Dni. Ini 5 Sektor Industri yang Jadi Fokus Jokowi di Era Digital. Koran Online. Di publish pada Rabu, 04 April 2018. Tersedia di

http://finance.detik.com/ind ustri/d-3952581/ini-5sektor-industri-yang-jadifokus-jokowi-di-era-digital. 
Diakses pada 18 Desember 2018.

Paul Krugman. A New Industrial Revolution: The Rise of Robots. Majalah Online. The New York Times Company, 2013. Tersedia di https://truthout.org/authors /paul-krugman/page/2/ Akses pada 27 Desember 2018 pukul 22:02.

Sakina Rakhma Diah S. Dukung Revolusi Industri 4.0 Komputasi Awan Jadi Faktor Penting. Koran Olnine. Di publish pada 25 Oktober 2018. Tersedia di https://ekonomi.kompas.co $\mathrm{m} / \mathrm{read} / 2018 / 10 / 25 / 12361$ 4926/dukung-revolusiindustri-30-komputasiawan-jadi-faktor-penting. 